\title{
Asmada (Vitis Vinifera L.) Adventif Kök Taslaklarının Farklılaşmasının İncelenmesi
}

\author{
Investigation on Differentiation of Adventitious Root Primordia in \\ Grapevine (Vitis vinifera L.)
}

\begin{abstract}
Özet
Araştırma, asmada (Vitis vinifera L.) adventif köklerin gövde dokularından farklılaşmasını mikroskobik düzeyde belirlemek amacına yönelik olarak temel bir çalışma niteliğinde gerçekleştirilmiştir. Köklendirme ortamında bekletilen Cabernet Sauvignon çeşidinin çelikleri kalınlıklarına (çap 1 cminin altı veya üstü) göre ayrılıp bazal kısımlarından $4-5 \mathrm{~cm}$ uzunluğunda kesilerek FAA (formalin \%10, etanol \%50 ve glasiyel asetik asit \%5) ortamında muhafaza edilmiştir. 60-90 $\mu \mathrm{m}$ kalınlığında kesitlere ayrılan örnekler safranin ile boyanmıştır. Adventif köklerin gövde kesitini oluşturan dokuların iki farklı bölgesinden farklılaştığı tespit edilmiştir. İnce dal parçalarında $(c ̧ a p<1 \mathrm{~cm}) k o ̈ k$ taslakları iletken doku sisteminin dış tarafına yakın hücre gruplarının bulunduğu bölgelerden, kalın dal parçalarında $($ çap $>1 \mathrm{~cm})$ ise daha içte ve öze yakın bölgelerdeki hücre gruplarından farklılaşmıştır. Düzensiz bir hücre yığını halinde oluşan kallus, kambiyuma bitişik floem bölgesinden gelişmektedir. Birbirlerinden bağımsız şekillenen adventif kök ve kallus oluşumunun aynı zaman aralığında olduğu gözlenmiştir.
\end{abstract}

Anahtar Kelimeler: Asma, boyama, çelik, safranin, farklılaşma

\section{Abstract}

The research was carried out as a basic study to determine localization of adventitious roots differentiated in the stem
Gönderilme Tarihi :

Kabul Tarihi
16 Mart 2021

14 Haziran 2021 
tissues of the grapevine (Vitis vinifera L.) at the microscopic level. The cuttings of Cabernet Sauvignon kept in rooting medium were grouped by their thickness (more or less than $1 \mathrm{~cm}$ in diameter) and $4.5 \mathrm{~cm}$ long basal parts were kept in FAA (formalin 10\%, ethanol 50\% and glacial acetic acid $5 \%$ ). Samples cut into sections with a thickness of 60-90 $\mu \mathrm{m}$ were stained with safranin. It was determined that the adventitious roots are differentiated from two different regions of the stem tissues. In the thin samples (diameter $<1 \mathrm{~cm}$ ), root primordia formed in the regions close to the outside of the conductive tissue system, while in the older cuttings (diameter $>1 \mathrm{~cm}$ ) they were differentiated from the cells in more inner region close to pith. Callus, formed as an irregular cell mass, is developed from the phloem region adjacent to the cambium. Formation of adventitious root and callus, which are shaped of independently each other, is within the same time frame.

Key words: grapevine, staining, cutting, safranin, differentiation

\section{GİRIŞ}

Bitkileri çoğaltma insanoğlunun başlıca uğraşlarından biridir. Son yıllarda yapılan araştırmalar çeşitli bitki büyüme düzenleyicilerinin veya bazı kimyasalların çoğaltma üzerine etkilerini araştırmaya odaklanmıştır. Adventif köklerin oluşumu, bitkilerin çelikle çoğalması ve büyümeleri için önemlidir. Geniş bir tanımı olan adventif kökler terimi dal ve gövde parçalarından kaynaklanan kökleri ifade eder. Çelikler ile çoğaltmada istenen şey, çelikte adventif köklerin şekillenmesiyle yeni bir kök sisteminin oluşmasıdır. Çünkü çelik üzerinde sürgünün meydana gelmesini sağlayacak yapı (tomurcuk) zaten mevcuttur. Adventif kök oluşumunun indüksiyonu, birçok bitki türünün klonal çoğaltılmasına izin verir (Hartmann ve ark., 1990). Bu süreç genotiplere göre değişmekle birlikte genellikle odunsu yapılarda daha zordur (Hackett, 1988).

Adventif kökler farklı dokulardan ve sonuç olarak farklı hücre tiplerinden gelişirler. Her zaman iletim dokularına komşu hücrelerden gelişirler. Hipokotil çevreteker, floem ve ksilem parankima, genç sekonder floem veya floem hücrelerine yakın kambiyum hücrelerinden meydana gelebilirler (Bellini ve ark., 2014). Adventif kökler önceden oluşmuş ve yara-teşvikli olmak üzere iki tiptir. Önceden oluşmuş kök öncülleri ve primordiyumları sürgünler hala ana bitki üzerinde iken doğal şekilde oluşurlar. Bunlar sürgünler çelik halinde uygun çevre koşulları altına yerleştirilene kadar dinlenme halinde kalırlar. Yara-teşvikli kökler ise kesim yüzeyinde bulunan hücreler zararlandığında bir tepki olarak başlar (Hartmann ve ark., 1990).

Yeni adventif kök oluşumundaki gelişmeler genellikle 4 aşamaya ayrılabilir (Hartman ve ark., 1997): 1) spesifik farklılaşmış hücrelerin geri farklılaşması (dediferansiasyon), 2) iletim demetlerinin yanındaki belli hücrelerden ya da yeniden farklılaşma (rediferansiasyon) sonucunda meristematik hale gelen iletim dokularından kök öncüllerinin oluşması, 3) kök öncüllerinden organize kök taslaklarının (taslakları) gelişmesi ve 4) sürgün dokusundan dışarıya doğru kök taslaklarının büyümesi ve çıkması ve ayrıca kök taslağı ile çeliğin iletim dokuları arasında köke ait iletim dokusunun oluşması.

Kökler gövdeden çıkmadan önce meydana gelen kök taslaklarının oluşumu ve şekillenmesi noktasında anatomik gözlemler sınırlıdır. Filiti ve ark. (1987) farklı Punus klonlarının in vitro köklenmesini inceledikleri çalışmada köklerin kallus oluşturmaksızın doğrudan kambiyum yakınındaki floem parankima hücrelerinden geliştiğini ifade etmiştir. Jásik ve De Klerk (1997) in vitroda elma gövde kesitlerinde köklerin primer ışında yer alan ksilem etrafındaki isodiyametrik sitoplasmik hücre halkasının bir kısmından çıktığını göstermiştir. Euclayptus globulus'un in vitro üretilmiş köklerin ya eski iletim dokusundan ya da yeni oluşan ksilemden gelişebileceği saptanmıştır (Calderón Baltierra ve ark., 2004). In vitro adventif köklenmenin MM 106 elma anacinda kambiyum bölgesinde ve floeme bitişik gerçekleştiği Naija ve ark. (2008) tarafından bildirilmiştir. Amissah ve ark. (2008) Quecus bicolor ve $Q$. macrocarpa çelikleri üzerinde yaptıkları araştırmada kök taslaklarının sekonder floemin üretken dokusu içerisinde başladığını saptamıştır. Philippa ve ark. (2015) ökaliptus 
(E. camaldulensis) çelikleri üzerine mikro kesim ve boyama tekniklerini kullanarak yaptıkları araştırmada adventif köklerin sadece kambiyum tabakasının yanlarından oluştuğunu ortaya koymuştur.

Vegetatif çoğaltılan bir tür olan asmanın çeliklerinin köklenme kapasitesi hakkında araştırmalar genelikle büyümeyi düzenleyici maddelerin (Schumann ve Uhl 1975; Keeley ve ark., 2004; Machado ve ark., 2005) veya farklı yetiştirme ortamlarının (Sengel ve ark., 2012) etkisinin belirlenmesi üzerine yoğunlaşmaktadır. Asma çeliklerinde adventif kök oluşumunun başlangıcı ve bu kök taslaklarının gövdeyi oluşturan dokuların hangi bölgelerinden oluştuğu üzerine yapılan araştırmalar ise yeterli düzeyde değildir. Fujii (1955) ve Han (1983) araştırmalarında asma çeliklerinde kök taslaklarının orijini üzerinde ilk gözlemleri yapmıştır.

Günümüzde örneklerin mikroskop altında incelenmesini sağlayan yeni mikroteknik yöntemler geliştirilmiştir. Özellikle sert ve odunsu yapıdaki örneklerde ince kesit almayı sağlayan yöntemler (mikrotom) ve boyama teknikleri kalın parafin kesitlerinde belirgin olmayan hücreler arasındaki farklılıkların gözlemlenebilmesini sağlayabilmektedir. Asma çeliklerinden alınacak ince kesitlere boyama teknikleri uygulanarak adventif köklerin farklılaşmasının anatomik olarak incelenmesi hem gövde üzerinde kök taslaklarının şekillemesini ortaya çıkaracak hem de asma köklenmesi üzerine yapılacak farklı uygulamaların etki mekanizmalarının ayrıntılı bir şekilde anlaşılmasına katkı sağlayacaktır. Bu araştırma, asma (Vitis vinifera L.) türünde adventif köklerin hangi gövde dokularından farklılaştığını mikroskobik düzeyde belirlemek amacına yönelik olarak gerçekleştirilmiştir. Ayrıca adventif köklerdeki farklılaşma sonrası değişiklikler anatomik olarak ortaya konulmuştur.

\section{MATERYAL ve YÖNTEM}

Kış dinlenme döneminde alınan Cabernet Sauvignon (Vitis vinifera L. cv.) çelikleri üzerinde iki göz bulunacak şekilde hazırlandıktan sonra köklendirme ortamına alınmış (2:1 torf:perlit) ve 60 gün süreyle $24^{\circ} \mathrm{C}$ ve $\% 70$ nemde gelişimleri sağlanmıştır. Toplamda 100 adet çelik dikilmiştir.

\section{Örneklerin alımı ve muhafazası}

Çeliklerden gelişen sürgünlerinin büyümesinin durmasının arkasından bitkiler sökülmüş ve kökler kesilerek uzaklaştırılmıştır. Bitkilerin bazal kısımları 4-5 cm uzunluğunda kesilerek içerisinde FAA (Formalin \%10, etanol \%50 ve glasiyel asetik asit \%5) bulunan 100'er ml'lik ışık geçirgenliği düşük kahverengi şişelerde muhafaza edilmiştir. Çeliklerin çap uzunluğuna bağlı olarak kök gelişim noktalarının (epiderme yakın veya öze yakın) tespiti için iki gruba ait 30'şar bazal kısım saklanmıştır.

\section{Mikrotom Kesitleme için Numune Hazırlama}

Mikrotom ile kesitlere ayırmak için, muhafaza ortamından çıkarılan örnekler çap büyüklügüne bağlı olarak hazırlanmıştır. Çapı $1 \mathrm{~cm}$ ve üstündeki örnekler dört eşit pasta dilimi şeklinde bölümlere kesilmiştir. Dilimleme işleminde küçük ağızlı el makası (Felco, İsviçre) kullanılmıştır. Kesit alma işlemine başlamadan önce incelenecek olan numuneler üzerindeki köklerin bulunduğu bölgeler, stereo mikroskop altında ok uçlu iğneler ve bisturi yardımıyla temizlenmiştir. Bu temizleme sırasında özellikle kök çıkış bölgeleri etrafında oluşan kallus dokusu kök çıkış noktalarına zarar vermeden uzaklaştırılmıştır. Bu işlem incelenecek numunelerdeki dokuların yumuşamaması için içerisinde $\% 50$ etanol-\%50 saf su bulunan ortamda gerçekleştirilmiştir. Kesmeden önce, oda sıcaklığında kurutulan numunelerin yüzey kısmı bantla kaplanmıştır. Bu işlem ince kesit alma sırasında dokuların dağılarak iç içe geçmesine engel olmaktadır.

\section{İnce Kesit Hazırlama}

Mikroskobik incelemelerin başarıyla yapılabilmesi için kesitlerin çok ince alınması büyük önem taşımaktadır. $\mathrm{Bu}$ amaçla klasik sürgülü yarı otomatik bir mikrotom (ReichertJung, Almanya) kullanılmıştır. Alınan kesitlerin kalınlığ ortalama $60-90 \mu$ m'dur. Bu şekilde ince kesitlerin alınmasını sağlayabilmek için çok keskin bıçaklar kulanılmış ve bu bıçaklar sıklıkla değiştirilmiştir. Mikrotom bıçağı 
50 ile $100 \mu \mathrm{m}$ arasında bir kesit kalınlığına ayarlandıktan sonra örneklerin yüzeyine $\% 98$ etanol damlatılmış ve ıslanmış bir sulu boya fırçası yardımıyla örneğin üzerindeki fazlalık alınarak bıçak kaydırılmıştır. Bu işlem bıçak temas noktasının ıslanmasını sağlamakta ve alınan kesidin kıvrılmasına engel olmaktadır. Kesitler boyama prosedürüne geçmeden önce içerisinde \%98'lik etanol bulunan petri kaplarına alınmıştır. Alınan numuneler mikroskop altında ön incelemeye alınarak mikrotom bıçağının kesici kenarından gelebilecek iz ve çatlaklar açısından kontrol edilmiş ve bu tip numuneler boyama testine alınmamıştır.

\section{Boyama Testi için örneklerin hazırlanması}

60-90 $\mu \mathrm{m}$ kalınlığında alınan örneklere safranin boyama yöntemi uygulanmıştır (Bond et al. 2008). Boyama yönteminde aşağıdaki prosedür uygulanmıştır.

-Saf su ile üç kez yıkama,

$-1: 1$ oranında $\% 96$ lik etanol (10 dakika)

$-1 \mathrm{~g} / \mathrm{L}$ safranin solüsyonu (20 dakika)

Yapılan uygulama sonucunda safranin emilimi gerçekleșen ve yüzeyi boyanan örneklerde mikroskobik incelemeye geçilmiştir.

\section{Mikroskobik inceleme ve görüntüleme}

Kök taslaklarının oluşumunun tespit edilmesinde Olympus SZX7 mikroskop (Olympus, Almanya) kullanılmıştır. Mikroskopa bağlı dijital mikroskop kamerası (Olympus LC20) ile örneklerin görüntülenmesi ve fotoğraflarının bilgisayara aktarılması sağlanmıştır. Örnekler üzerinde yapılan mikroskobik incelemelerde LCmicro yazılımından faydalanılmıştır. Safranin emilimi gerçekleşen ve yüzeyi boyanan örnekler mikroskop altında alttan sşık alan bir düzleme yerleştirildiğinde ve yansıyan parlak ışığa (üsten aydınlatma) maruz bırakıldığında farklı tonlara boyanan bütün dokular net bir şekilde görülebilmektedir. Aksi takdirde dokuların mikroskopta tanımlanması ve görüntülenmesi güçleşmekte ve iyi fotoğraflanamamaktadır.

\section{BULGULAR}

'Cabernet Sauvignon' (Vitis vinifera L.) çeşidinde adventifköklerinin şekillenmesi ve hücre gruplarının oluşum bölgelerinin anatomik farklılaşması Şekil 1'de verilmiştir. Asma çeliklerinde adventif köklerin genellikle gövde kesitini oluşturan dokuların iki farklı bölgesinden şekillendiği tespit edilmiştir. Birinci olarak, iletken dokuların hemen dışında ve arasında bulunan hücre gruplarından (Şekil 1A), ikinci olarak da daha içte öz noktasına uzanan hücre gruplarından (Şekil 1B) farklılaşmaktadır. Gövde kesidinin her iki bölgesindeki hücre grupları bölünerek birçok yeni hücre g0ruplarını meydana getirmekte ve bu gruplar da kök taslakları haline dönüşmektedir. Gelişmesine devam eden yeni kök taslakları iletken doku sistemini oluşturarak en yakın iletken doku sistemine bağlanmaktadır. Kökün ucu, korteks ve epidemis içinden dışa doğru büyüyerek gövde ile bir dik açı teşkil edecek şekilde gövde kesitinden dışarı çıkmaktadır (Şekil 1C). Ayrıca, nadiren de olsa incelenen örneklerde kök oluşumlarının, öz ışınları, parankima ve öz gibi çeşitli dokulardan oluşan hücre gruplarından da şekillendiği görülmektedir (Şekil 1D). Asma çeliklerinde adventif köklerin oluşumu kısa sürede şekillenmiş ve asma çelikleri hızlı bir köklenme göstermiştir. İncelenen asma çeliklerinde kallus tabakası meydana gelmektedir. $\mathrm{Bu}$ tabaka parankima hücrelerinin düzensiz bir şekilde bir yığın halinde birikmesiyle görünür hale gelmektedir (Şekil 1E). Kallus tabakasını şekillendiren hücre yığınlarının oluştuğu doku, kambiyuma bitişik floem bölgesidir (Şekil 1F). Adventif kök oluşumu ile kallus oluşumu incelenen asma çeliklerinde aynı zaman çerçevesine gerçekleşmektedir.

İncelenen örneklerde çapı $1 \mathrm{~cm}$ 'in altındaki dal parçalarında kök başlangıçları iletken doku sisteminin dış tarafına yakın yerde $(\% 59,38)$, çapı $1 \mathrm{~cm}$ 'in üzerindeki dal örneklerinde ise derinden (öz ve öze yakın) ve çok defa iletken doku kambiyum ve öze yakın yerde meydana gelen hücre gruplarından $(\% 63,92)$ şekillenmektedir. 

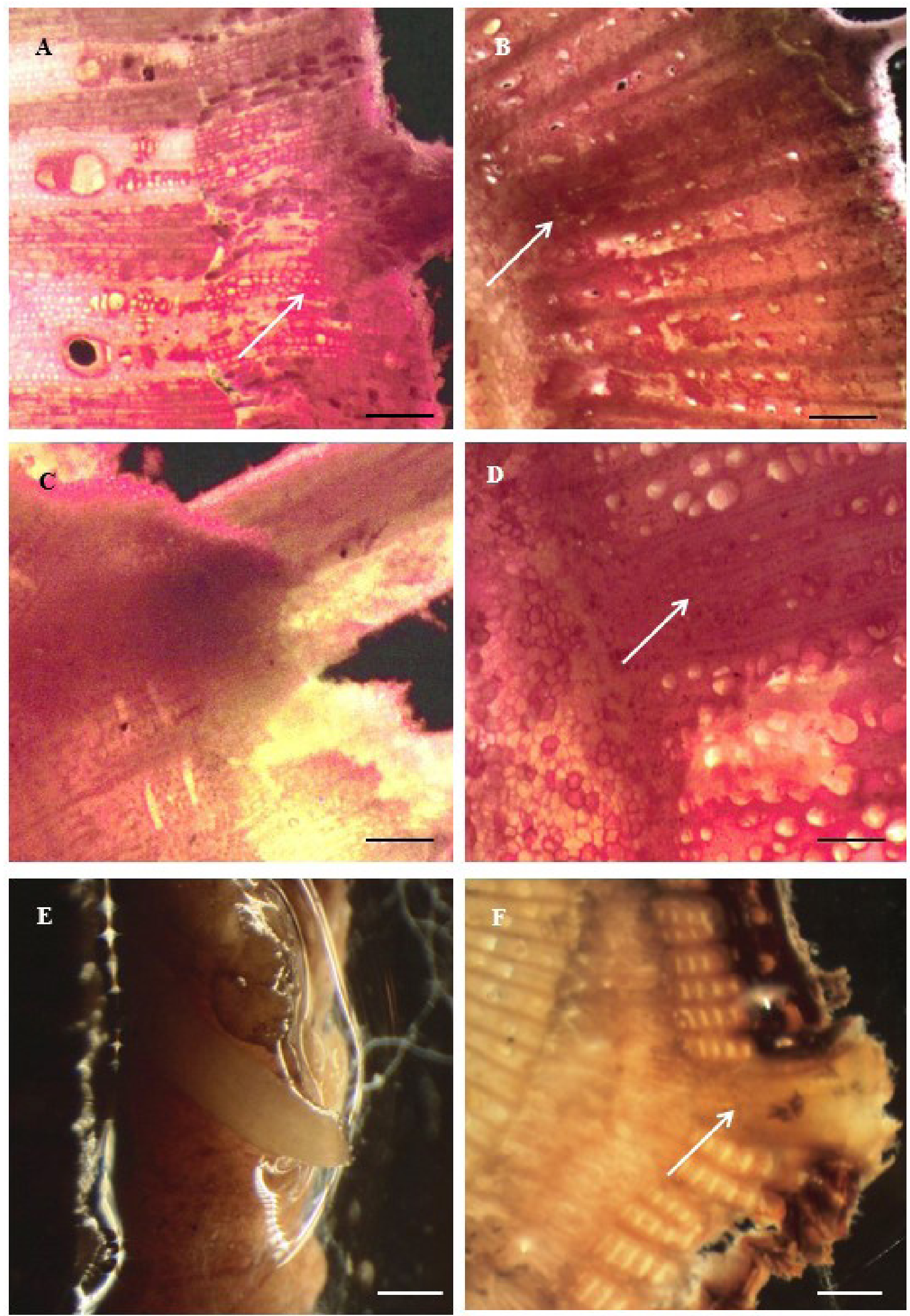

Şekil 1. Cabernet Sauvignon (Vitis vinifera L.) çeşidinde adventif köklerinin şekillenmesi ve hücre gruplarının oluşum bölgeleri (oklar hücre yığınlarını göstermektedir) Bar=200 $\mu \mathrm{m}$. 


\section{TARTIŞMA}

Farklı bitki türlerinde yapılan çalışmalar, dal ve gövde kısımlarından kaynaklanan adventif köklerin oluştuğu dokuların bitki türüne göre değiştiğini göstermektedir. $\mathrm{Bu}$ oluşumda özellikle kambiyum ve floemde bulunan meristematik hücrelerin daha etkili olabileceği ifade edilmektedir (Hayward, 1983).

Bazı bitkilerde (elma, ayva) kök yerinin gövdenin gelişmesi sırasında oluştuğu ve bunlarda çeliklerin hazırlandığı sırada kök yerlerinin mevcut olduğu bildirilmektedir. Bu bitkilere ait gövdeler çelik haline getirilip köklerin gelişmesi için elverişli ortama konuncaya kadar dinlenme halinde kaldıkları ve bunların meydana geldikleri yerlerin, gövde üzerindeki diğer adventif köklerin oluştukları yerlerle benzerlik gösterdiği ifade edilmektedir (Hartmann ve ark., 1990). Çalışmada incelenen asma örneklerinde adventif köklerin oluşumu tamamen örnekler alındıktan sonra başlamıştır yani önceden oluşmuş adventif kök taslağına sahip değildir (van der Lek 1924). Bellini ve ark. (2014) vegetatif çoğaltılan türlerin çoğunluğunda adventif kök oluşturmak için indüksiyon öncesi hücrelerin farklılaştığı bir safhanın bulunduğunu, buna karşılık Hartmann ve ark. (1990) kavak ve söğüt (Salix spp.) gibi türlerin dinlenme halinde adventif kök başlangıçlarının gövdelerinde bulunduğunu ifade etmiştir.

Vitis'in 1 yaşlı dallarındaki adventif kök oluşumunun ilk histolojik çalısmaları Favre ve Medard (1969) ve Favre (1973) tarafından gerçekleştirilmiş ve araştırıcılar dallarda "şişmenin" veya iki iletim demeti arasında yer alan (interfasikuler) kambiyumun hücre salkımları içerisindeki hipertropik çekirdeklerin ortaya çıkısıını ilk basamak olarak ifade etmiştir. Araştırıcılara göre kambiyum hücrelerinin periklinal bölünmesinin ardından ilk kök taslakları oluşmaktadır. Çalışmada alınan örneklerde de bu gözleme uygun şekilde, adventif kökler iletken dokuların hemen dışında ve arasında bulunan gruplar halindeki hücrelerden oluşmuştur. $\mathrm{Bu}$ hücre grupları bölünerek birçok yeni hücre gruplarını meydana getirerek kök taslakları haline gelişmesine devam etmiştir. Her hücre grubunda bölünme devam etmiş ve daha sonraki bir zamanda kök ucu görünür hale gelmiştir. Yeni kök taslağı da bir iletken doku sistemi meydana getirerek en yakın doku sistemine bağlı gelişimine devam etmiştir. Kökün ucu, korteks ve epidemis içinden dışa doğru büyüyerek gövde ile bir dik açı teşkil edecek şekilde dışarı çıkmıştır. Böylece gövdedeki adventif kökler endogen olarak meydana şekillenmiştir.

\section{SONUÇ ve ÖNERILLER}

'Cabernet Sauvignon' (Vitis vinifera L. cv.) çeşidinin çeliklerinde adventif kökler gövdeyi oluşturan dokuların iki farklı bölgesinden oluşmaktadır. Bunlar iletken dokuların hemen dışında bulunan hücre grupları ve öz noktasına uzanan hücre gruplarının farklılaştığı bölgelerdir. Her iki bölgedeki hücre grupları bölünerek birçok yeni hücre gruplarını meydana getirmekte ve bu gruplar da kök taslakları haline dönüşerek en yakın iletken doku sistemine bağlanmaktadır. Gövde dokuları üzerinde endogen olarak meydana gelen adventif kökler, korteks ve epidermis içinden dışa doğru büyüyerek gövde ile bir dik açı teşkil edecek şekilde dışarı çıkmaktadır. Genç asma dallarında kök oluşumunun iletken doku sisteminin dış tarafına yakın, yaşlı dallarında ise öze yakın daha derinden meydana gelmektedir.

\section{TEŞEKKÜR}

$\mathrm{Bu}$ çalışma Çanakkale Onsekiz Mart Üniversitesi Bilimsel Araştırma Projeleri Koordinasyon Birimince Desteklenmiştir. Proje Numarası: FBA-2018-1392. Makalede araştırma ve yayın etiğine uyulmuştur. Araştırmacılar araştırmaya ve yayına eşit derecede katkıda bulunmuştur.

\section{KAYNAKLAR}

Amissah, J.N., D.J. Jr, Paolillo and N. Bassuk. 2008. Adventitious root formation in stem cuttings of Quercus bicolor and Quercus macrocarpa and its relationship to stem anatomy. Journal of American Society of 
Horticultural Science, 133: 479-486. https://doi. org/10.21273/JASHS.133.4.479

Bellini, C., D.I. Pacurar and I. Perrone. 2014. Adventitious roots and lateral roots: similarities and differences. Annual Reviews of Plant Biology, 65: 639-666. https:// doi.org/10.1146/annurev-arplant-050213-035645

Bond, J., L. Donaldson, S. Hill and K. Hitchcock. 2008. Safranine fluorescent staining of wood cell walls. Biotechnic \& Histochemistry, 83: 161-71. https://doi. org/10.1080/10520290802373354

Calderón Baltierra, X., G. Montenegro and E. de García. 2004. Ontogeny of in vitro rooting process in Eucalyptus globulus. In Vitro Cell Development and Biology- Plant, 40: 499-503. https://doi.org/10.1079/ IVP2004559

Favre, J.M. 1973. Effets corrélatifs de factuers internes et externs sur la rhizogenés d'un clone de vigne (Vitis riparia $\times$ Vitis rupestris) 'in vitro'. Revue Générale de Botanique, 80: 279-361.

Favre, J.M. and R. Médard. 1969. Ontogénie des raciness adventives chez la vigne (Vitis vinifera L.) cultivée in vitro. Revue Générale de Botanique, 76: 455-467.

Filiti, N., N. Montuschi and P. Rosati. 1987. In vitro rhizogenesis: histo-anatomical aspects on Prunus rootstock. Advances in Horticultural Science, 1: 34-38.

Fujii, T. 1955. Origin and development of root primordia in grape cuttings. Journal of Japanese Society of Horticultural Science 24(3): 160-164.

Hackett, W.P. 1988. Donor plant maturation and adventitious root formation. In: Adventitious Root Formation In Cuttings. (Eds. T.D. Davis, B.E. Haissig and N. Sankhla), Dioscorides, Portland, Ore. pp 1128.

Han, Q-Q. 1983. The primary observation on anatomy of the adventitious root formation in grape cuttings. Journal of the Agricultural University of Hebei 6: 4548.
Hartmann, H.T., D.E. Kester and J.T. Davies, Jr. 1990. Plant propagation: Principles and practices. 5th ed. Prentice Hall, Englewood Cliffs, N.J.

Hayward, H.E. 1983. The Structure of Economic Plants, Mcmillan, New York, pp. 39-56.

Jásik, J. and G.J. De Klerk. 1997. Anatomical and ultrastuctural examination ofadventitious rootformation in stem slices of apple. Biologia Plantarum, 39(1): 7990. https://doi.org/10.1023/A:1000313207486

Keeley, K., J.E. Preece, B.H. Taylor and I.E. Dami. 2004. Effects of high auxin concentrations, cold storage, and cane position on improved rooting of Vitis aestivalis Michx. Norton Cuttings. American Journal of Enology and Viticulture 55(3): 265-268.

Machado, M.P, J.L.S. Mayer, M. Ritter and L.A. Biasi. 2005. Effects of indole-butyric-acid on the rooting ability of semihardwood cuttings of grapevine rootstock 'VR 043-43' (Vitis vinifera $\mathrm{x}$ Vitis rotundifolia). Revista Brasileira de Fruticultura, 27(3): 476-479. https://doi. org/10.1590/S0100-29452005000300032

Naija, S., N. Elloumi, N. Jbir, S. Ammar and C. Kevers. 2008. Anatomical and biochemical changes during adventitous rooting of apple rootstock MM 106 cultured in vitro. Comptes Rendus Biologies, 331: 518 525. https://doi.org/10.1016/j.crvi.2008.04.002

Philippa, H., I. Bryant, J. Stephen and I. Trueman. 2015. Stem anatomy and adventitious root formation in cuttings of Angophora, Corymbia and Eucalyptus. Forests, 6: 1227-1238. https://doi.org/10.3390/ f6041227

Schumann, F. and F. Uhl. 1975. On the use of auxins favouring root formation. Mitteilungen Klosterneuburg, 25:339-346.

Van der Lek, H. 1924. Root development in woody cuttings. Mededelingen Landbouwhogeschool Wageningen 28: 211-230. 